\title{
GrassView - the form and function of grass: a multimedia program
}

\author{
E.P. ASHLEY ${ }^{1}$, C. MATTHEW ${ }^{2}$ and J. HODGSON ${ }^{2}$ \\ ${ }^{1}$ Wanganui Regional Community Polytechnic, Private Bag 3020, Wanganui \\ ${ }^{2}$ Department of Plant Science, Massey University, Private Bag 11-222, Palmerston North
}

\begin{abstract}
GrassView - the form and function of grass is an interactive computer programme which uses video footage, narration, sound, computer based 3D animation, graphical displays of information, charts and quizzes to present a description of the morphology of a grass tiller and the implications for sward behaviour. The programme is designed for flexibility of use. In interactive mode it could be used for self-directive study, whereas in linear mode it could be video-projected as a presentation to a class of students or to an assembled group. It has been optimised to run under Windows 95 or NT 4.0 and is distributed as a CD.
\end{abstract}

Keywords: computer program, grass form and function, grass morphology, interactive program, leaf extension, multi-media, root formation, tiller formation

\section{Introduction}

The grass plant possesses a segmental morphology, whereby repeating units known as phytomers are budded off from a growing point near ground level. A grass shoot or tiller is in effect a chain of phytomers in different stages of development. This morphology confers some unique behavioural properties, and is the basis for the grazing tolerance of grasses and for the fact that sheets of turf may be transplanted with ease. A clear conceptual understanding of the morphology of the grass tiller and the consequent implications for behaviour is invaluable to all those involved in the use of grass, whether for pastoral or turf purposes.

A keen student can glean this information from research papers and text books (see e.g., Langer 1963; Jewiss 1993). However the microscopic scale, the complexity of the structures involved, and the difficulties of conceptualising how structures in a text-book photomicrograph change over time has meant that the information has remained largely inaccessible to all but specialist pasture agronomists. Within the last five years, developing computer technology has made it possible for this type of information to be displayed in an easyto-follow and user-friendly fashion. GrassView - the form and function of grass is a computer program which uses still photographs and diagrams, video segments, time-based animation, and narration, to describe how a grass tiller functions.

\section{Program design}

GrassView - the form and function of grass is an interactive educational package that offers a self-paced learning experiences as well as a linear information display. Careful attention has been directed towards the integration of relevant material in an easy to use graphical interface. The designated target audience was secondyear university students in agriculture. Critical in the design of GrassView was the necessity to use the program as an adjunct instructional tool to illustrate concepts through animation that are sometimes hard to grasp when illustrated in a static manner. The program was also designed to meet the full range of the student learning curve through a capacity to review information in both linear and non-linear formats. Versatility of navigation for relating abstract and concrete concepts is integral to the learning process.

The interactive user mode is intended for selfdirected study. This mode is useful for the student as a review or study aid. The student is enabled to navigate forwards and backwards, as well as jump from section to section. The linear presentation mode is intended to work as an adjunct teaching aid for the lecturer. The lecturer could present the $\mathrm{CD}$ in the linear mode via overhead projection to an entire class. In addition, both current degree programme design with emphasis on flexibility (Anderson \& Hodgson 1997) and the concept of a "seamless" education system where students may join a degree programme in the second year after transferring from another institution mean that students may join a class without all the relevant background. In such situations it is not feasible for a lecturer to tutor students individually and it would be useful to be able to assign a student to check out and review the $\mathrm{CD}$ as a means to cover information with which the student is unfamiliar.

The Form and Function of Grass was developed on Macintosh and PC computers using a suite of MacroMedia authoring tools. It has been optimised to run under Windows 95 or NT 4.0 and is distributed as a $\mathrm{CD}$. The user interacts with the $\mathrm{CD}$ through a graphical user interface. This has been designed for an intuitive 
Figure 1 Graphical interface of GrassViewshowing titles of the six sections and user-directed navigation options.

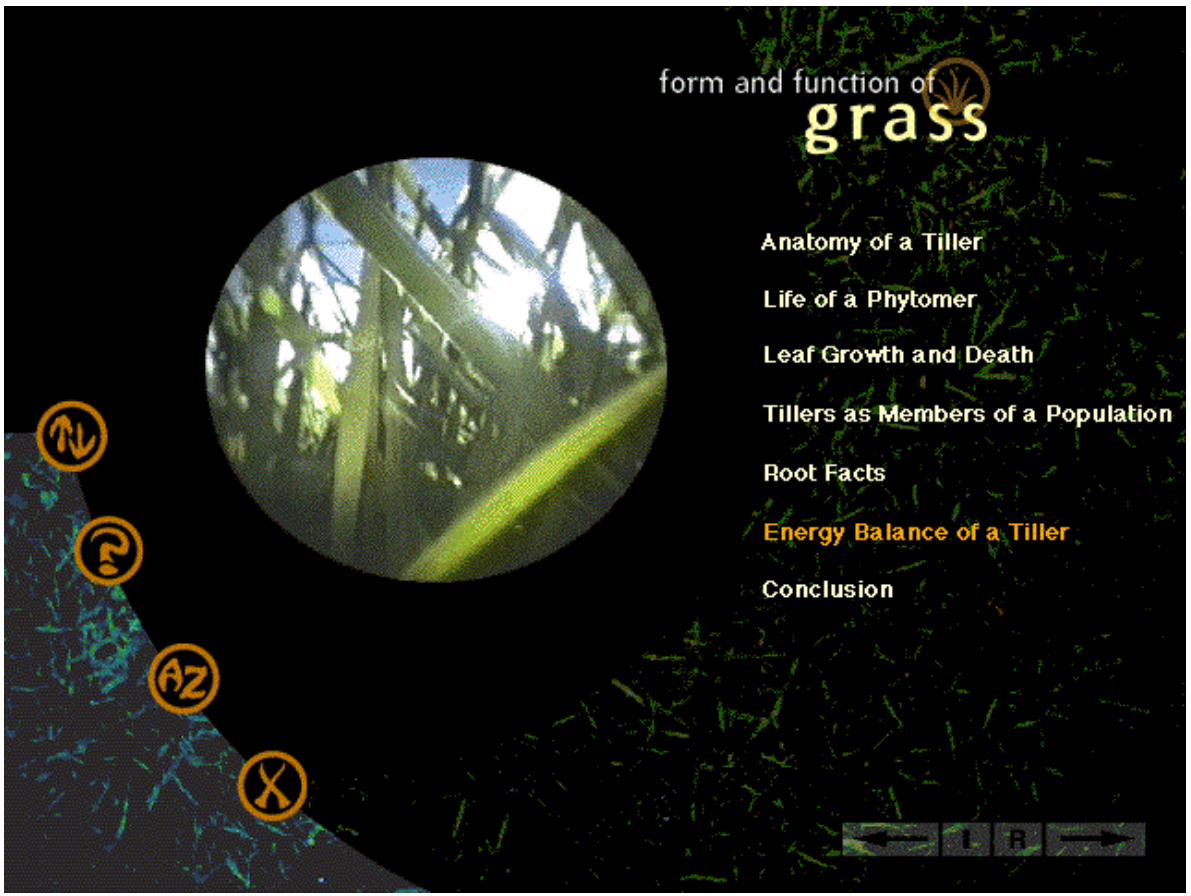

Figure 2 Sample of information content included in section of GrassView entitled Root facts. The figure shows extent of root development at successive nodes on the tiller axis of perennial ryegrass. Based on the data of Matthew \& Kemball (1997).

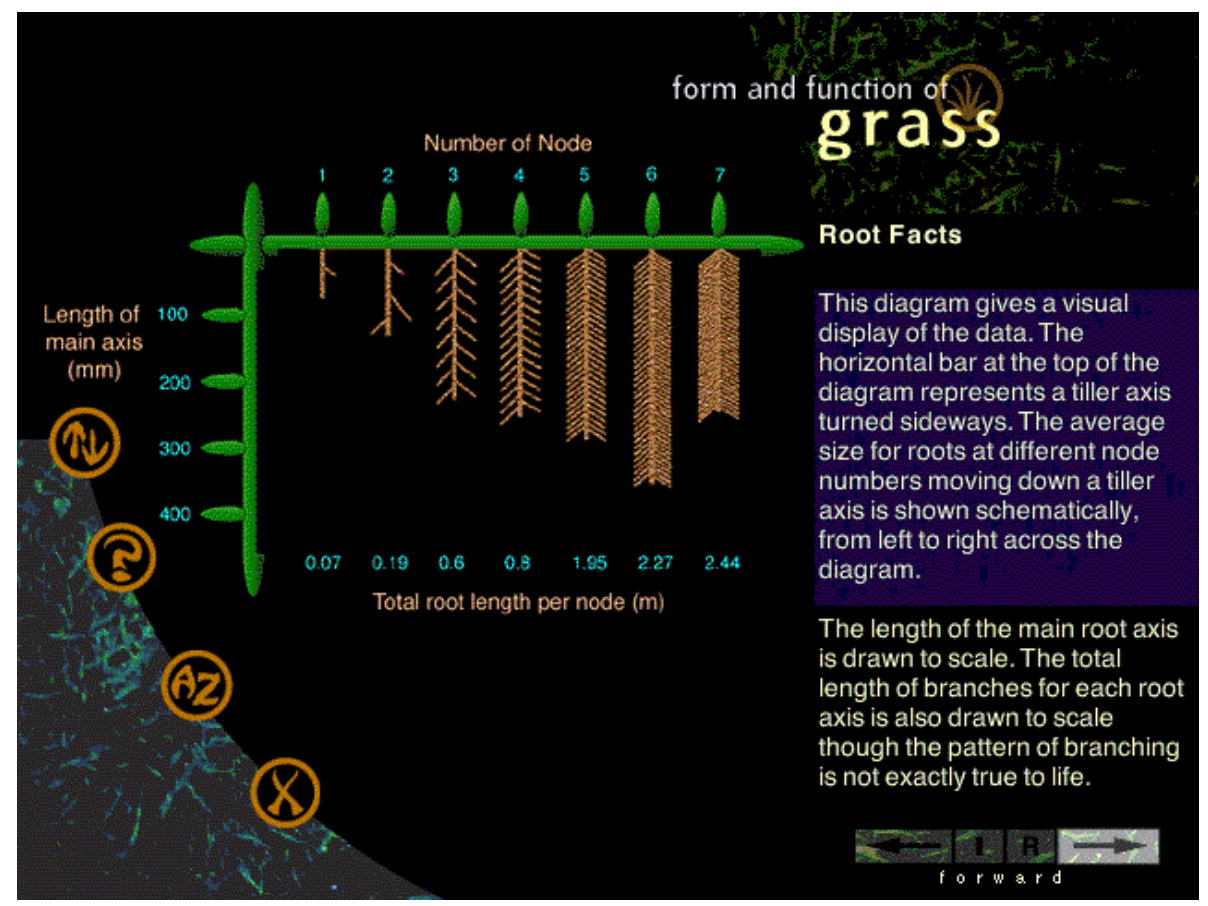


audio visual experience utilising video footage, narration, sound, computer-based 3D animation, graphical displays of information, charts and quizzes. The user navigates through this interactive using a combination of keyboard and mouse actions that allow for self-paced learning and review.

\section{Content}

The main programme content is organised into six sections (Figure 1). The first two sections describe the anatomy of a grass tiller and how phytomers at different stages of development contribute to the overall function of the tiller. There follow sections dealing with leaf, tiller and root formation, respectively. The concluding section discusses the energy balance of a grass tiller. The focus, therefore is on the functionality of tillers in grazed (or mown) swards. The programme includes, for example, extended discussion of how rate of leaf elongation, leaf senescence, and net herbage accumulation changes with herbage mass during a regrowth cycle, with the capacity for users to "perform an experiment" to see how rates of leaf elongation and death will change at different levels of herbage mass. In order to preserve the focus on morphology and functionality of the vegetative tiller, topics such as reproductive growth and fungal endophyte are not covered, however. These could well be the subject of separate programmes at a later date, depending on the level of interest in GrassView.
A second feature of the content is the use of up-todate research information. For example details of the amount of root development at successive phytomers on the tiller axis of ryegrass were published for the first time by Matthew \& Kemball (1997) and this information (Figure 2) is included in the section of GrassView entitled Root Facts.

\section{ACKNOWLEDGEMENTS}

We gratefully acknowledge the following as contributors to the planning, development and programming of GrassView: J. Gaither, R. Templer, C. Bolter, M. Algie, M. Dawson, R. Lefeber, P. Probine.

\section{REFERENCES}

Langer, R.H.M. 1979. How grasses grow (2nd edition). Edward Arnold, London. 66 pp.

Jewiss, O.R. 1993. Shoot development and number. Chapter 5 In: A. Davies, R.D. Baker, S.A. Grant \& A.S. Laidlaw. Eds. Sward measurement handbook, $2^{\text {nd }}$ edition. The British Grassland Society, Reading.

Hodgson, J.; Anderson, R.D.; Kirkman, J.H. 1997. A new degree for land based industries at Massey University, New Zealand. Proceedings of the XVIII International Grasslands Congress: in press.

Matthew, C.; Kemball, W.D. 1997. Allocation of carbon14 to roots of different ages in perennial ryegrass (Lolium perenne L.) Proceedings of the XVIII International Grasslands Congress: in press. 
